\title{
"Weak" ultrasonic pre-treatment on anaerobic digestion of flocculated activated biosolids
}

\author{
C.P. Chu ${ }^{\mathrm{a}}$, D.J. Lee ${ }^{\mathrm{a}, *}$, Bea-Ven Chang ${ }^{\mathrm{b}}$, C.S. You ${ }^{\mathrm{b}}$, J.H. Tay ${ }^{\mathrm{c}}$ \\ a Department of Chemical Engineering, National Taiwan University, Taipei, 10617 Taiwan \\ ${ }^{\mathrm{b}}$ Department of Microbiology, Soochow University, Taipei, 111 Taiwan \\ ${ }^{\mathrm{c}}$ Division of Environmental \& Water Resources Engineering, School of Civil \& Structural Engineering, \\ Nanyang Technological University, 639798 Singapore
}

Received 31 July 2001; accepted 15 November 2001

\begin{abstract}
This study examined how "weak" ultrasonic pre-treatment affects anaerobic digestion of waste biosolids, treated with a cationic polyelectrolyte flocculant. In relation to pre-treatment, the term "weak" used refers to the fact that the total ultrasonic energy input to biosolids is insufficient to fully disrupt its floc structure or the cell walls, as described in the literature. Methane production potential, floc characteristics (size, morphology and $\zeta$-potential) and process parameters (chemical oxygen demands and oxidative-reductive potentials) were monitored, as the digestion was tested. The presence of polyelectrolyte flocculants enhanced methane production within 6 days of digestion (phase I), but inhibited the digestion thereafter (phase II). Following pre-treatment by sonication $(0.33 \mathrm{~W} / \mathrm{mL}, 20 \mathrm{~min})$, the methane productions of both original and flocculated biosolids significantly increased. The underlying mechanisms of weak ultrasonic pre-treatment are discussed. (C) 2002 Elsevier Science Ltd. All rights reserved.
\end{abstract}

Keywords: Anaerobic digestion; Sonication; Methane production; Floc characteristics

\section{Introduction}

Anaerobic digestion is an extensively adopted means of stabilization for reducing biosolids' volume and producing bio-gas [1]. Interactions between complex ecological systems and organic compounds that govern the detailed mechanism have attracted much interest [2-5]. Chemical flocculants are often added to biosolids to enhance their sedimentation rate before digestion. Dentel et al. [6] showed that the applied polyelectrolyte concentrates in the discharged waste biosolids to up to $10 \mathrm{~kg} /$ ton dry solids (DS). Chu et al. [7] demonstrated that flocculation to the charge neutralization point would markedly increase the rate of thermal pyrolysis of biosolids. Gossett et al. [8] noted that the ratio of methane production to the

\footnotetext{
*Corresponding author. Tel.: + 886-2-363-5230; fax: + 8862-362-3040.

E-mail address: djlee@ccms.ntu.edu.tw (D.J. Lee).
}

destruction of volatile solids fell when organic coagulants were present in an anaerobically digested wastewater biosolids. However, El-Manouni et al. [9] found that the synthetic polyelectrolyte did not inhibit the biomass activity, but promoted metabolic transfer rate.

Pre-treatment has been employed to increase anaerobic digestion, and has included the use of thermal energy [10], alkali [11], ultrasound [12], and mechanical shearing [13]. Some works discussed combined treatment using alkaline and ultrasound [14]. Chu et al. [7] observed the changes in chemical, physical, and biological characteristics of waste-activated biosolids, subjected to ultrasonication. Mechanical disintegration of biosolids can greatly transform insoluble organics into a soluble form. By replacing the use of intracellular enzyme in hydrolysis, the rate constraints on digestion efficiency are destroyed [15,16]. Lee and Müller [17] compared the advantages and shortcoming of certain forms of pre-treatment. 
Chemical conditioners are frequently adopted in solid-liquid separation. However, their role in the anaerobic digestion of biosolids has not been definitely understood. Ultrasound is a pressure wave that causes cavitation in solution, leading to rise to local temperature up to $1000^{\circ} \mathrm{C}$ and a pressure above greater than 500 bars. Such cavitation can dissemble cell walls. In Chu et al. [7], the ultrasound was noted to disrupt fully the floc structure and release a large proportion of organics from the sludge particles. This process is efficient, but exhausts much energy if applied in a field [18]. This investigation examines the effects of applying "weak" ultrasound pre-treatment on the floc characteristics of anaerobically digested, activated biosolids using cationic polyelectrolyte as the conditioner. The "weak" ultrasound refers to sonic energy insufficient to fully disrupt the floc structure (only $\frac{1}{3}$ of the previously proposed energy level in Ref. [7]). An insufficient ultrasound dose does not directly release insolubles into the suspension, but allows the organics to be more easily attacked by the hydrolyzed enzyme.

\section{Experimental}

\subsection{The samples}

Waste-activated biosolids were taken from a wastewater treatment plant at the Presidential Enterprise Co., Taoyuan, Taiwan. The biosolids had a yellow brown appearance and a mild odor. Biosolids sediment, settled for $1 \mathrm{~h}$ was tested. The total solid content was $9390 \mathrm{mg} /$ L. An Accupyc Pycnometer 1330 (Micromeritics, USA) measured the density of dried solids in the biosolids at $1470 \mathrm{~kg} / \mathrm{m}^{3}$ with a relative deviation of $<0.5 \%$. The $\mathrm{pH}$ value of the original biosolids was around 6.7.

\subsection{Flocculation conditioning and sonication}

Cationic polyelectrolyte T3052 was obtained from Kai-Guan Inc., Taiwan, in which the cationic polyacrylamide component had a molecular weight of $10^{7}$ and a charge density of $20 \%$. The biosolids sample was first placed into a standard mixing vessel with a paddle mixer. A pre-determined quantity of flocculant solution $(0.2 \%$ by weight $)$ was then slowly poured into the mixing vessel with $200 \mathrm{rpm}$ stirring for $5 \mathrm{~min}$, followed by $50 \mathrm{rpm}$ stirring for another $20 \mathrm{~min}$. The polymer flocculation did not noticeably alter the $\mathrm{pH}$ value of the suspension.

The original and the conditioned biosolids samples were sonicated in a $500 \mathrm{~mL}$ beaker using a cell-disrupter (SONICATOR XL-2020, Heat system-Ultrasonics, Inc.) $2 \mathrm{~cm}$ above the bottom of the beaker. The ultrasound frequency was $20 \mathrm{kHz}$. The sonication power was $0.33 \mathrm{~W} / \mathrm{mL}$ and the sonication period was $20 \mathrm{~min}$. The temperature of the biosolids was maintained at $25^{\circ} \mathrm{C}$ in a water bath to prevent possible temperature effects. Chu et al. [7] showed that at this power, the size of most of the flocs was degraded after $60 \mathrm{~min}$ of sonication. The feasibility of using a shorter period of sonication, $20 \mathrm{~min}$, at a power level of $0.3 \mathrm{~W} / \mathrm{mL}$ to pre-treat the biosolids was considered. The following sections label the original biosolids as sample $\mathrm{O}$; the cationic polymer flocculated biosolids (40 g-T3052/kg-DS) as sample F; the original biosolids subject to sonication as sample OS, and the flocculated sample $\mathrm{F}$ following sonication, as sample FS.

\subsection{Characterization of biosolids}

The floc size was measured by a particle sizer (LS230, Coulter). The mean floc size of original biosolids was about $58 \mu \mathrm{m}$. The $\zeta$-potentials of biosolids flocs were obtained using a zetameter (Zeta-Meter System 3.0, Zeta-Meter Inc., USA). The result for the original biosolids was $-13.6 \mathrm{mV}$. The surface charge of the biosolids flocculated with T3052 was neutralized at approximately $15 \mathrm{~g}$-T3052/ $\mathrm{kg}$-DS of the dose, and the $\zeta$ potential of the flocs at $40 \mathrm{~g}-\mathrm{T} 3052 / \mathrm{kg}-\mathrm{DS}$ was $+18.1 \mathrm{mV}$.

\subsection{Anaerobic digestion and related tests}

The biosolids were anaerobically digested following the procedures of Chang et al. $[19,20]$. All experiments were undertaken using $25 \mathrm{~mL}$ serum bottles in an anaerobic glove box (Forma Scientific, model $1025 \mathrm{~S} /$ N) filled with $85 \% \mathrm{~N}_{2}, 10 \% \mathrm{H}_{2}$, and $5 \% \mathrm{CO}_{2}$. Biosolids $5 \mathrm{~mL}$ (original or flocculated) mixed with $1 \mathrm{~mL}$ anaerobes $\mathrm{K} 8$ and $4 \mathrm{~mL}$ medium (compositions listed in Table 1) were poured into the serum bottles. K8 was collected from the bottom sediment at some sampling sites in the Tam-Shui River (near Taipei), in March 1998. The K8 was adapted by adding $0.1 \mathrm{ppm}$ polychlorobenzene and medium (listed in Table 1) to $500 \mathrm{~g}$ sediment at 14-day intervals under static incubation at $35^{\circ} \mathrm{C}$ excluding light for over $2 \mathrm{yr}$. The $\zeta$ potential of

Table 1

The components of the medium used during incubation

\begin{tabular}{ll}
\hline Components & Concentration $(\mathrm{g} / \mathrm{L})$ \\
\hline $\mathrm{K}_{2} \mathrm{HPO}_{4}$ & 0.35 \\
$\mathrm{KH}_{2} \mathrm{PO}_{4}$ & 0.27 \\
$\mathrm{NH}_{4} \mathrm{Cl}$ & 2.7 \\
$\mathrm{CaCl}_{2} \cdot 2 \mathrm{H}_{2} \mathrm{O}$ & 0.1 \\
$\mathrm{MgCl}_{2} \cdot 2 \mathrm{H}_{2} \mathrm{O}$ & 0.1 \\
$\mathrm{FeCl}_{2} \cdot 6 \mathrm{H}_{2} \mathrm{O}$ & 0.02 \\
Yeast extract & 12 \\
Reszurin (reductants) & 0.001 \\
\hline
\end{tabular}


the biosolids did not vary much due to the presence of anaerobe K8. Serum bottles were then capped with butyl rubber stoppers and wrapped in aluminum foil to prevent photolysis. These bottles were incubated at $35^{\circ} \mathrm{C}$ without shaking. Chang et al. $[19,20]$ claimed that the optimal temperature for the growth of $\mathrm{K} 8$ is $35^{\circ} \mathrm{C}$, which was used throughout this study. Three serum bottles were randomly chosen for sampling at fixed time intervals. These sample bottles were then abandoned.

Methane production was quantified by gas chromotography (Sigma 3B Perkin-Elmer) with a packed column $(200 \times 0.5 \mathrm{~cm}, 80 / 100$ porapal Q; Supecol, Bellefonte, PA) and a flame-ionization detector. The column's temperature was maintained at $90^{\circ} \mathrm{C}$ while the injector and the detector were maintained at $55^{\circ} \mathrm{C}$. Nitrogen was the carrying gas, at a flow rate of $20 \mathrm{~mL} /$ min. An integrator (HP3396 Series II) was used to integrate the peak area, determining the methane concentration.

The oxidative and reductive potentials (ORP) of the biosolids were measured using an ORP meter (HI 9017 Hanna). The total chemical oxygen demand (TCOD) of the biosolids was measured with a direct reading spectrophotometer (DR/2000, HACH, USA). The TCOD of the original biosolids (with $\mathrm{K} 8$ and the medium) was measured at $7990 \mathrm{mg} / \mathrm{L}$. The chemical oxygen demand of the filtrate was measured at $479 \mathrm{mg} /$ $\mathrm{L}$, and was referred to as SCOD (soluble chemical oxygen demand).

The Luceferin-Luciferase method was used to measure quantitatively the adenosine triphosphate (ATP) concentrations in the biosolids, to serve as indices of the microbial density. An $0.5 \mathrm{~mL}$ aliquot of activated biosolids (pre-mixed with $\mathrm{K} 8$ and medium) was automatically pipetted with the necessary reagents into a cuvette. The reagents used here include the extraction enzyme for ATP purchased from NRB and LUMIT PM (luciferase dissolved in a LUMIT buffer solution). The contained enzyme-substrate complex, luciferase-luciferin, converted the chemical energy of ATP into light via a stoichiometric reaction in several seconds, and the luminometer (BIOCOUNTER M 2500, LUMAC, The Netherlands) read the emitted bioluminescence in relative luminescence units (RLUs). Using the tests with standard ATP solutions, $1 \mu \mathrm{g} / \mathrm{L}$ of ATP yielded a light intensity of 1036 RLU [21]. The ATP concentration in the suspension containing only the anaerobe $\mathrm{K} 8$ (no biosolids) was $0.42 \mu \mathrm{g} / \mathrm{L}$. All the other testing samples (reported herein) were the biosolids (original or flocculated) mixed with $\mathrm{K} 8$ and the medium.

The maximum relative errors are around $5 \%$ for methane production amount, zeta potential, and SCOD/ TCOD measurements, $7 \%$ for ATP measurements, and $<10 \%$ for ORP measurements.

\subsection{Confocal laser scanning microscopy}

A confocal laser scanning microscope (CLSM) (OLYMPUS BX50) was used to identify the internal floc structure. This microscope was equipped with an image processor (OLYMPUS FV5 PSU) and an Argon laser source to stimulate fluorescence. The biosolids floc was imaged with a $10 \times$ objective using the FLUOVIEW software, version 3.0. The microscope scanned the samples at a fixed depth and digitized the image obtained.

Biosolids samples for this analysis (CLSM) were first fixed with 3\% paraformadehyde in phosphorous buffer saline (PBS) to maintain the cell morphology following the death of microorganisms. The fixed samples were then embedded in low-melting-point agar (with a melting point of $75^{\circ} \mathrm{C}$ and a gelling point of $38^{\circ} \mathrm{C}$ ) and followed by fluorescent in situ hybridization (FISH). This study employed two different DNA probes, Eub 338 (labeled by rhodamine) and Arc 915 (labeled as tetrachlorofluorescein). Eub 338 and Arc 915 were used to detect most eubacteria and methanogenic bacteria in anaerobic biosolids, respectively. The stained samples were washed three times using a hybridization buffer solution to remove extra probes.

\section{Results and discussion}

\subsection{Methane production}

Fig. 1 illustrates the accumulated methane production over 100 days of digestion. (Note: The relative error for the data presented herein is rather small, as mentioned above, eliminating the need for error-bars in the figure.) As Fig. 1 illustrates, during the first 6 days, sample $\mathrm{F}$ generates methane at a higher rate than does sample $\mathrm{O}$. Hypothesis test reveals that this statement is acceptable at a confidence of $95 \%$. Restated, as asserted following El-Manouni et al. [9], the presence of polyelectrolyte accelerated digestion. This finding is attributable to the easier digestion of the flocculant molecules than of the original biosolids.

Over time, the digestion of sample $\mathrm{F}$ starts slowing and produces less methane than does sample $\mathrm{O}$. The overall yield at the end of the test (day 100) is $88 \mathrm{~g}^{-\mathrm{CH}_{4} /}$ $\mathrm{kg}$-DS for sample $\mathrm{F}$ and $143 \mathrm{~g}-\mathrm{CH}_{4} / \mathrm{kg}$-DS for sample $\mathrm{O}$. The presence of polyelectrolyte therefore suppresses methane production, agreeing with the conclusion of Gossett et al. [8] that the polyelectrolyte can inhibit digestion. This observation is also confirmed using hypothesis test at a confidence level of $95 \%$. The decline in digestion efficiency for flocculated sludge is attributable to the mass transfer resistance within the flocculated sludge matrix for the reactants, and the end-products of the later stage of digestion. 


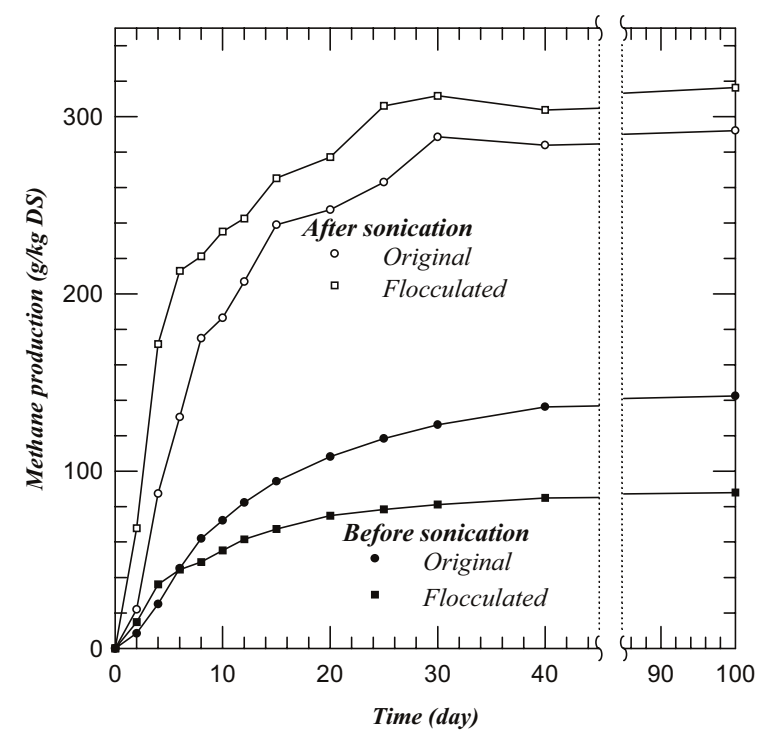

Fig. 1. Accumulative amount of methane production.

Sonication pre-treatment greatly increased both the production rate and ultimate yield of methane. The 6day methane production amount increased from around $45 \mathrm{~g}-\mathrm{CH}_{4} / \mathrm{kg}$-DS for the untreated biosolids sample $\mathrm{O}$ and $44 \mathrm{~g}-\mathrm{CH}_{4} / \mathrm{kg}$-DS for sample $\mathrm{F}$ to $130 \mathrm{~g}-\mathrm{CH}_{4} / \mathrm{kg}$-DS for sample OS and to $213 \mathrm{~g}-\mathrm{CH}_{4} / \mathrm{kg}$-DS for sample FS. Enhancements of $290 \%$ and $480 \%$ are attained. Meanwhile, the corresponding ultimate yields increased from $143 \mathrm{~g}-\mathrm{CH}_{4} / \mathrm{kg}$-DS for sample $\mathrm{O}$ and $88 \mathrm{~g}-\mathrm{CH}_{4} / \mathrm{kg}$-DS for sample $\mathrm{F}$ to $292 \mathrm{~g}-\mathrm{CH}_{4} / \mathrm{kg}-\mathrm{DS}$ for sample OS and $316 \mathrm{~g}$ $\mathrm{CH}_{4} / \mathrm{kg}$-DS for sample FS. The methane yields increase by $104 \%$ and $260 \%$ for the original and the flocculated biosolids, respectively. Accordingly, while the presence of polyelectrolyte in long-term tests retards anaerobic digestion (comparing sample $\mathrm{O}$ with sample $\mathrm{F}$ ), ultrasonic pre-treatment significantly enhances digestion. Furthermore, the presence of polyelectrolyte further increases the ultimate yield of sample FS by approximately $10 \%$ over that of sample OS. These findings are too apparent hence no hypothesis tests were conducted for the ultrasonically treated samples.

\subsection{SCOD/TCOD ratio}

Fig. 2 presents the SCOD/TCOD ratios during digestion. The TCOD value adopted here is that of the original biosolids $(7990 \mathrm{mg} / \mathrm{L})$. The ratios for the original and flocculated biosolids are 0.06 and 0.08 , respectively. The presence of polyelectrolyte slightly increases the soluble COD, correlating with the initial promotion of the anaerobic digestion (Fig. 1). This ratio approaches a plateau value of $0.12-0.14$ after 6 days of digestion. The SCOD yields the balance between the

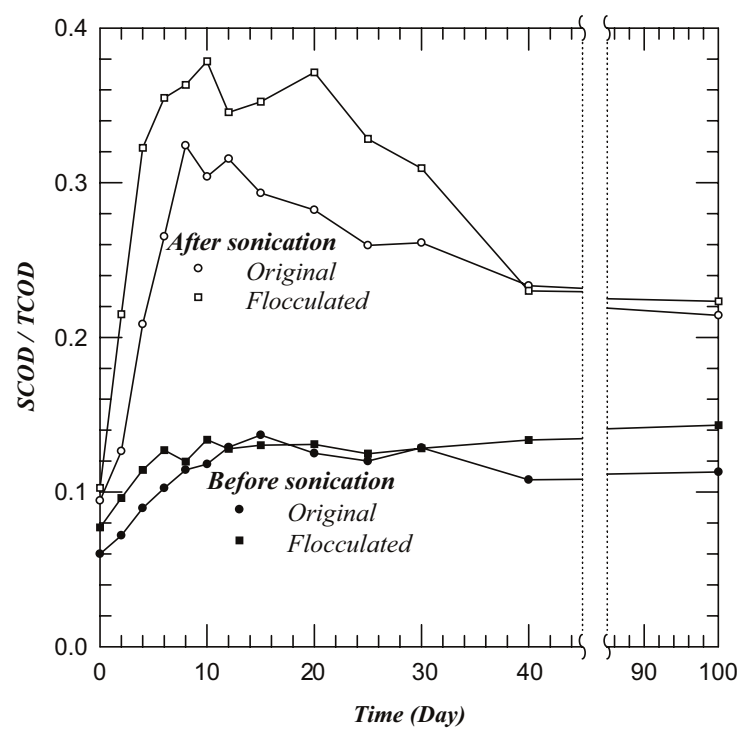

Fig. 2. Time evolution of SCOD/TCOD during anaerobic digestion of sludge.

hydrolysis and digestion of organics. Hydrolysis dominates during the initial stage of digestion (up to 6 days). Thereafter, the hydrolysis reaches a rate similar to that of methane production, yielding an almost constant SCOD. The digestion is complete in 40 days. The SCOD remaining in the suspension cannot be further digested although its value remains high. The SCOD/TCOD ratio thus is unrelated to the methane production kinetics and cannot be employed as a lone index for biodigestability.

Sonication pre-treatment can only slightly increase the SCOD/TCOD ratio from $0.06-0.08$ to about 0.1 . The ratio climbs rapidly in the subsequent digestion stage, however, to $0.32-0.38$ on day $8-10$. This notable increase in soluble COD level corresponds to the enhancement in methane production shown in Fig. 1. Afterwards, the SCOD/TCOD gradually declines and approaches a plateau of 0.22 .

\subsection{ORP and ATP measurements}

Fig. 3 displays the changes in the ORP values measured during digestion, at the beginning of which, the ORP value for the original biosolids was $-239 \mathrm{mV}$. When polyelectrolyte and/or ultrasound are applied to sample $\mathrm{O}$, the medium becomes less reductive. During anaerobic digestion, the microorganisms reduce the ORP of the medium to a level suitable for forming volatile fatty acids and methane, as indicated by the decline of ORP over the first 4-6 days of digestion. Finally, all samples approach a plateau of about $-300 \mathrm{mV}$, establishing a stably reductive environment for methane production. 


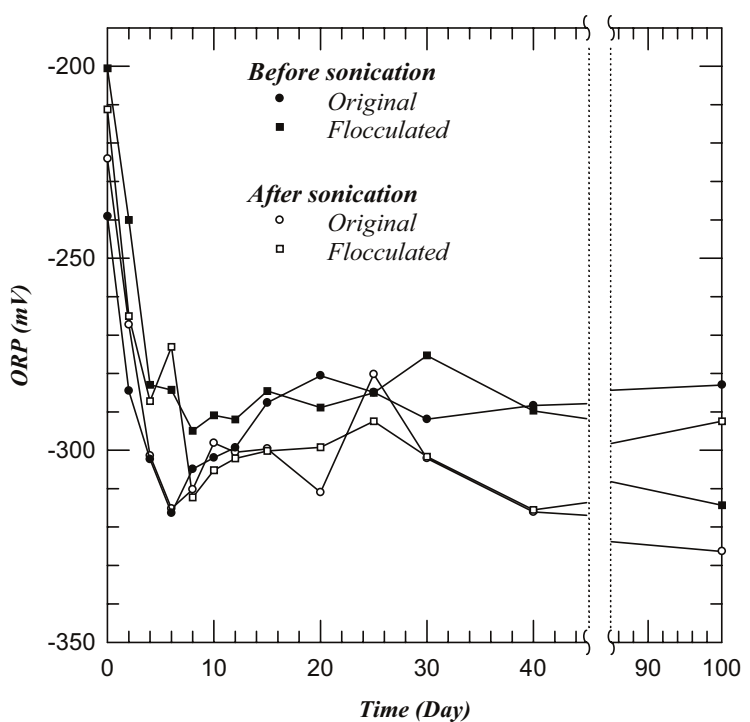

Fig. 3. Time evolution of oxidation-reduction potentials during the anaerobic digestion.

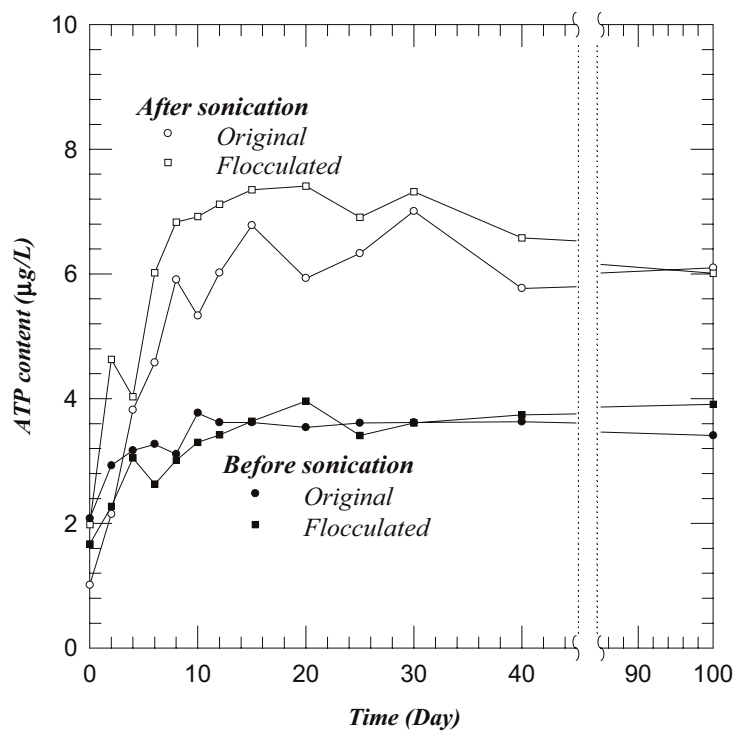

Fig. 4. Time evolution of ATP content during the anaerobic digestion.

Chang et al. [19] proposed that the change in ORP may be attributable to growth in the anaerobic consortium in biosolids. Fig. 4 presents the measured ATP concentration, which follows the activity of the biomass in the biosolids. Sonication reduces the ATP level of the original sludge from 2 to around $1 \mu \mathrm{g} / \mathrm{L}$, implying a marked reduction in microbial activity in the sonicated sample. However, polyelecrolyte protects the microbes from the ultrasonic field. In digestion tests, the ATP concentration increases with time, and attains a constant value at $3.7-4 \mu \mathrm{g} / \mathrm{L}$, for the untreated biosolids

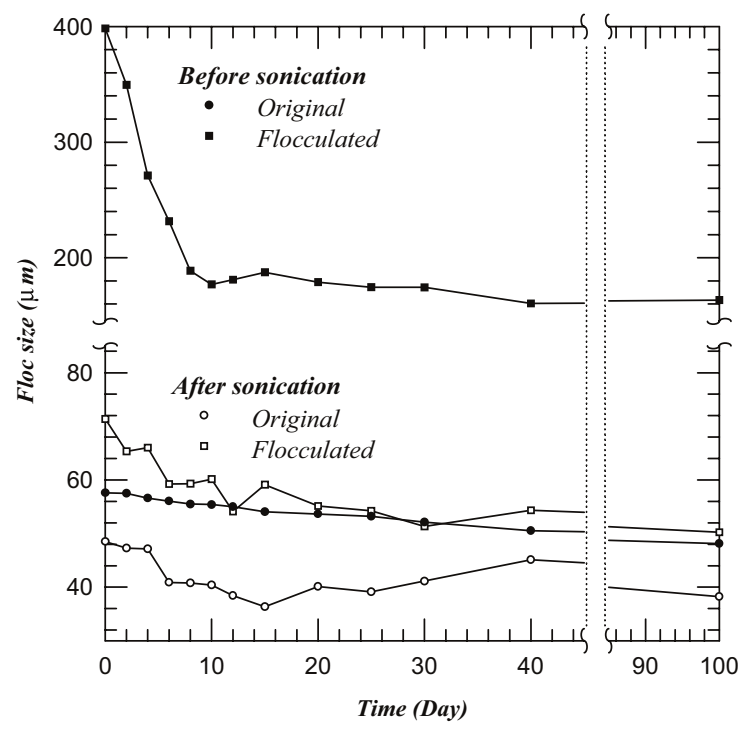

Fig. 5. Floc size change during the digestion.

and around $6 \mu \mathrm{g} / \mathrm{L}$ for the sonicated biosolids after day 10. A higher ATP level for sonicated biosolids implies the presence of more active anaerobes in the biosolids, associated with the observed increased methane production in Fig. 1. Although the initial drop in ORP is correlated with the increase in ATP content during digestion, as Figs. 1 and 3 illustrate, the growth in the anaerobic consortium does not necessarily remain the only factor that determines the ORP values.

\subsection{Changes in floc characteristics}

Fig. 5 presents the mean floc sizes of the original and flocculated biosolids. At a dose of $40 \mathrm{~g}-\mathrm{T} 3052 / \mathrm{kg}-\mathrm{DS}$, the floc size increases from 57 to $400 \mu \mathrm{m}$, implying the occurrence of favorable flocculation. Sonication can reduce the floc size down to a level of below $70 \mu \mathrm{m}$ in the flocculated sample. The matrix constructed with polymer flocculation is thus mostly deteriorated following sonication. In all the cases, the floc size falls as digestion proceeds. The reduction in floc size for sample $\mathrm{O}$ is weak while that for sample $\mathrm{F}$ is significant with a reduction by more than $50 \%$ due to 10 days of digestion. However, digestion only slightly reduces the floc size of the ultrasonically treated samples. Interestingly, the floc size reaches a plateau after about 10 days of digestion. Subsequent digestion cannot further degrade the floc global structure.

Fig. 6 displays the time evolutions of the $\zeta$-potentials for the biosolids. The $\zeta$-potential of biosolids flocs changes sign from -14 to $+18 \mathrm{mV}$ after flocculation showing that the applied dosage exceeds the chargeneutralization point. However, $\zeta$-potentials decline following sonication. The original biosolids flocs exhibit 


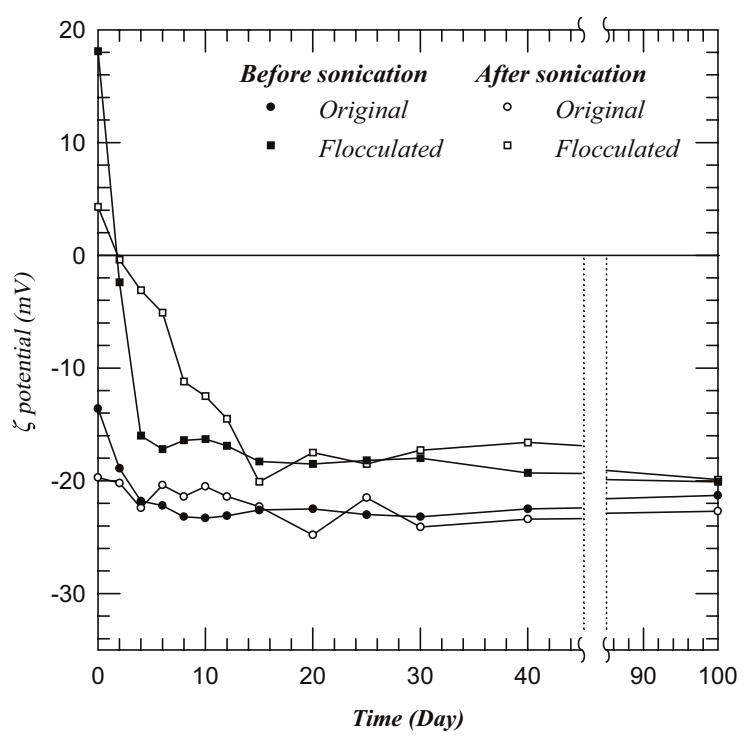

Fig. 6. The $\zeta$-potentials of sludge flocs during digestion.

a more negative charge $(-20 \mathrm{mV})$ while the flocculated surface is almost neutral $(+4 \mathrm{mV})$. Ultrasound thus degrades the floc structure and establishes a new surface of particles reducing the average surface charge of the floc.

As digestion proceeds, the $\zeta$-potentials for all biosolids samples slowly converge to a constant at about $-20 \mathrm{mV}$, which correlates with the value for the sonicated, original biosolids. Restated, the surface charges for the digested samples are similar to those for the fragments of the sonicated original biosolids. The fragments in the original biosolids flocs may be the socalled "microflocs" mentioned in the literature [22]. The microflocs are relatively strong and can be disrupted by neither sonication nor digestion. The mass transfer limitation within these microflocs mostly contributes to the digestion efficiency if the whole process is masstransfer controlled.

\subsection{Internal structure of flocs}

Fig. 7 presents the CLSM images of the original and the ultrasonically treated samples before digestion. High bioactivity is noted in the original and the flocculated biosolids, and the latter possess a more compact interior structure (Figs. 7a and b). This finding relates to the microscopic findings (figures not shown). Fig. 7c shows bioactive, scattered clusters for sample OS. The ultrasound can therefore partially inactive the biomass in the flocs, although the action of the polyelectrolyte appears partially to protect the microorganisms from inactivation in the formed matrix (Fig. 7d). As Fig. 7d also shows, the ultrasound has led to a matrix with a loose structure, after exposure to ultrasound.

\subsection{Roles of "weak" sonication on anaerobic digestion}

"Weak" ultrasonic pre-treatment revealed the following facts. As Figs. 1-6 reveal, the digestion of activated biosolids, original or flocculated, involves the following two stages. Before day 10 marked changes in all process characteristics are noted: SCOD/TCOD and ATP concentrations increase; ORP value and floc size fall; and the $\zeta$-potentials of the particle surface become more negative (or less positive). During this period (phase I), methane production reaches $63-73 \%$ of the ultimate yield. Thereafter, all these process parameters slowly converge and reach a plateau state, while the remaining $27-37 \%$ of methane is produced over a $20-30$ day period (phase II). Phase I digestion gains most of the benefit from the digestion of biosolids, independent of the presence of flocculants or the application of ultrasound.

The presence of flocculant molecules can enhance phase-I digestion, probably attributable to their utilization by bacteria as a carbon source. In phase II, the flocculant molecules suppress digestion. "Weak" ultrasound pre-treatment can markedly enhance digestion efficiency for both original (sample OS) and flocculated biosolids (sample FS). The SCOD/TCOD ratio only slightly rises from $6-8 \%$ to about $10 \%$, suggesting that the weak ultrasound pre-treatment cannot efficiently dissolve the insoluble organics in biosolids. However, this ratio increases significantly to $32-38 \%$ during phase I digestion. Obviously, the exposure to ultrasound has caused the organics to be attacked more readily by the hydrolyzed enzyme. Although the total ultrasonic energy input is insufficient to disrupt fully the floc interior and effectively release the organics from the solid phase, it satisfactorily enhances the subsequent anaerobic digestion processes. This finding is inconsistent with the literature, suggesting that pre-treatment directly transforms the available organics into soluble forms [14].

Furthermore, the presence of polyelectrolyte can further increase the ultimate yield for sample FS by approximately $10 \%$ over that of sample OS. Notably, the polyelectrolyte is present in sample FS with a weight percentage of around $4 \%$. Taking the mass loss in biosolid digestion as $30-40 \%$ of the original weight, as is common, the excess $10 \%$ methane production for sample FS can be regarded as the end-product of digesting the polyelectrolyte. These results imply that the ultrasound not only helps to hydrolyze the biosolids particles, but also facilitates digestion of the polyelectrolyte molecules.

The flocs generated in natural systems possess a multilevel structure. The activated biosolids floc formation model of Gorczyca and Ganczaeczyk [23] involves primary particles $(1-2 \mu \mathrm{m})$, flocculi $(5-10 \mu \mathrm{m})$, microflocs (several tens $\mu \mathrm{m}$ ), and whole flocs $(100-200 \mu \mathrm{m}$ ). The results of this study suggest that weak ultrasonic 


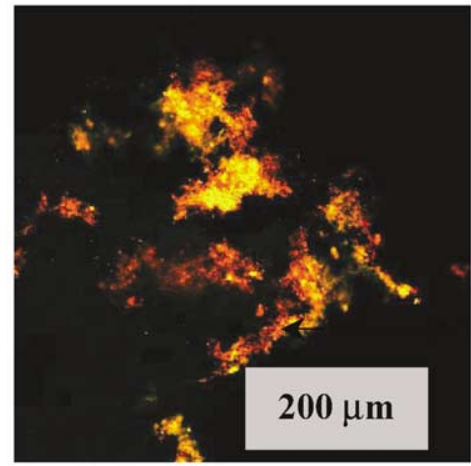

(a)

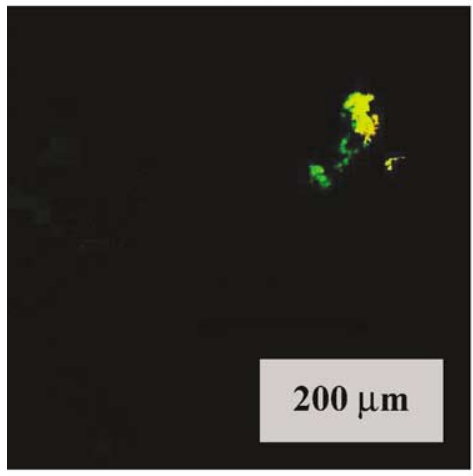

(c)

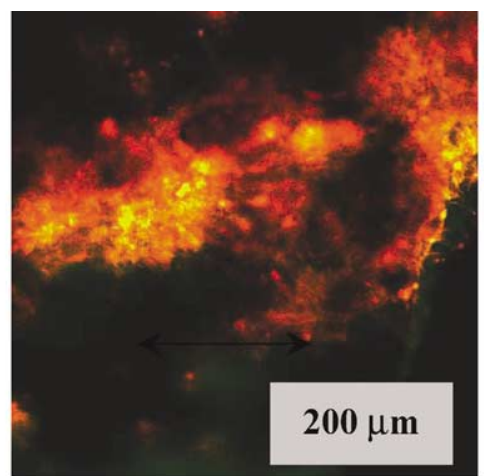

(b)

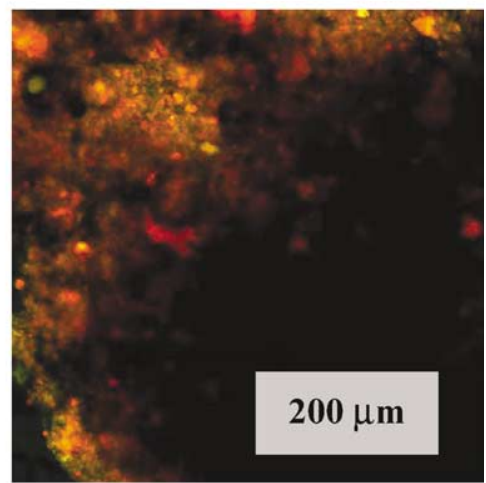

(d)

Fig. 7. Images from confocal laser scanning microscope of samples before digestion: (a) sample O, day 0; (b) sample F, day 0; (c) sample OS, day 0; (d) sample FS, day 0.

pre-treatment did not break down the global floc in the original sample, $\mathrm{O}$, into constituent microflocs (of size $50 \mu \mathrm{m}$ and zeta potential $-20 \mathrm{mV}$ ). The flocs in all the sludge samples following digestion, except those for sample F, resemble the microflocs. Sample F, following 100-day digestion, also exhibits a $\zeta$ potential of around $-20 \mathrm{mV}$. The much greater floc size noted in Fig. 5 $(160 \mu \mathrm{m})$ simply suggests that the residual polymer chains can still bind most microflocs. However, it exhibits the highest digestion rate among all the investigated samples as the ultrasound breaks most of the bonds of the flocculated network and results in a loose matrix in the interior of the flocculated samples, as revealed in the CLSM images (Fig. 7d). Consequently, anaerobic digestion cannot degrade the basic structure of microflocs, which can be considered as the fundamental units governing the digestion efficiency.

\section{Conclusions}

This work examined the effects of "weak" ultrasonic pre-treatment on anaerobic digestion of waste biosolids, conditioned with a cationic polyelectrolyte flocculant. Parameters like methane production, size, morphology, reductive potentials, and $\zeta$-potential and chemical oxygen demands were monitored during digestion. Two distinct stages (phases I and II) were observed. The presence of polyelectrolyte flocculants enhanced methane production within 6 days of digestion (phase I), but inhibited digestion thereafter (phase II). Weak sonication $(0.33 \mathrm{~W} / \mathrm{mL}, 20 \mathrm{~min})$ significantly enhanced the methane production of both original and flocculated biosolids, without fully degrading the floc structure. CLSM images display that the flocculated/sonicated biosolids (sample FS) exhibit a looser structure than non-flocculated/sonicated biosolids and thus possess the highest methane production rate and ultimate yield.

\section{References}

[1] Parkin GF, Owen WF. Fundamentals of anaerobic digestion of wastewater biosolids. $\mathbf{J}$ Environ Eng 1986;112:867-920. 
[2] Govind R, Flaherty PA, Dobbs RA. Fate and effects of semivolatile organic pollutants during anaerobic digestion of biosolids. Water Res 1991;25:547-56.

[3] Hickey RF, Switzenbaum MS. Thermodynamics of volatile fatty acid accumulation in anaerobic digesters subject to increases in hydraulic and organic loading. Res J Water Pollut Control Fed 1991;63:141-4.

[4] Li YY, Mizuno O, Miyahara T, Noike T, Katsumata K. Ecological analysis of the bacterial system in a full-scale egg-shaped digester treating sewage biosolids. Water Sci Technol 1997;36(6-7):471-8.

[5] Rinzema A, Boone M, Van Knippenberg K, Lettinga G. Bactericidal effect of long chain fatty acids in anaerobic digestion. Water Environ Res 1994;66:40-9.

[6] Dentel SK, Chang L-L, Raudenbush DR, Junnier RW, Abu-Orf MM. Influence of polymer chemistry on biosolids and the environment. Alexandria, VA, USA: Water and Environmental Research Foundation, 2000.

[7] Chu CP, Lee DJ, Chang BV, Liao CS. Observations on changes in ultrasonically treated waste activated sludge. Water Res 2001;35:1038-46.

[8] Gossett JM, McCarty PL, Wilson JC, Evans DS. Anaerobic digestion of biosolids from chemical treatment. Res J Water Pollut Control Fed 1978;50:533-42.

[9] El-Manouni R, Leduc R, Guiot SR. Influence of synthetic and natural polymers on the anaerobic granulation process. Water Sci Technol 1998;38(8-9):341-7.

[10] Li YY, Noike T. Upgrading of anaerobic digestion of waste activated sludge by thermal pretreatment. Water Sci Technol 1992;26(3-4):857-66.

[11] Lin JG, Rajan RV, Ray BT. Low-level chemical pretreatment for enhanced sludge solubilization. J Water Pollut Control Fed 1989;61:1678-83.

[12] Tiehm A, Nickel K, Neis U. The use of ultrasound to accelerate the anaerobic digestion of sewage sludge. Water Sci Technol 1997;36(11):121-8.
[13] Kopp J, Müller J, Dichtl N, Schwedes J. Anaerobic digestion and dewatering characteristics of mechanically excess sludge. Water Sci Technol 1997;36(11):129-36.

[14] Chiu YC, Chang CN, Lin JG, Huang SJ. Alkaline and ultrasonic pretreatment of sludge before anaerobic digestion. Water Sci Technol 1997;36(11):155-62.

[15] Müller JA. Sewage sludge disintegration as a key step in sewage sludge minimization. Water Sci Technol 2000; 41(8):123-30.

[16] Müller JA. Pretreatment processes for the recycling and reuse of sewage sludge. Water Sci Technol 2000;42(9): 167-74.

[17] Lee DJ, Müller J. Preliminary Treatment. In: Spinoda S, Vesilind PA, editors. From Sludge to Biosolids, International Water Association, UK, 2001.

[18] Müller JA. Sludge Pre-treatment: methods, applications, problems and efficiency. In: Post-conference workshop on sludge management. Taipei, Taiwan: IWA Conference on Sludge Management, 2001.

[19] Chang B-V, Zheng JX, Yuan SY. Effects of alternative electron donors and inhibitors on pentachlorophenol dechlorination in soil. Chemosphere 1996; 33:313-20.

[20] Chang B-V, Su CJ, Yuan SY. Microbial hexachlorobenzene dechlorination under three reducing conditions. Chemosphere 1998;36:2721-30.

[21] Chu CP, Lee DJ, Chang BV, Liao CS. Using ATP bioluminescence techniques for monitoring microbial activity in sludge. Biotech. Bioeng., accepted, $2001 \mathrm{~b}$.

[22] Jorand F, Zartarian F, Thomas F, Block JC, Bottero JY, Villemin G, Urbain V, Manem J. Chemical and structural (2D) linkage between bacteria within activated sludge flocs. Water Res 1995;29:1639-45.

[23] Gorczyca B, Ganczarczyk J. Structure and porosity of alum coagulation flocs. Water Qual Res J Can 1999; 34:653-66. 